\title{
Adenocarcinoma of the Appendix and a Meckel's Diverticulum in a Case of Acute Appendicitis
}

\author{
Petr Lochman ${ }^{a} \quad$ Robert Čáp ${ }^{a} \quad$ AlešKohout $^{b}$ \\ a Department of Field Surgery, Faculty of Military Health Sciences, University of Defence, \\ ${ }^{b}$ Department of Pathology, University Hospital, Hradec Králové, Czech Republic
}

\section{Dear Editor,}

Primary adenocarcinomas of the appendix are rare, with an incidence of less than $0.5 \%$ of all malignant gastrointestinal tumours [1-3]. Signet ring cell carcinomas represent $4-11 \%$ of appendiceal cancer and are hardly ever diagnosed before surgery $[1,4,5]$. Patients are mostly operated on for acute appendicitis or other cause of acute abdomen. We report the case of a young man with acute appendicitis where the inflamed appendix and a Meckel's diverticulum were removed. Histology revealed a poorly differentiated adenocarcinoma of the appendix with districts of signet ring cells. According to our knowledge, no such case has been published so far.

A 36-year-old man presented with a history of pain in the right lower abdominal quadrant over $34 \mathrm{~h}$. Physical examination revealed rebound tenderness in the right iliac fossa and an axillorectal temperature difference. Laboratory tests showed leukocytosis (white blood cell count: $14,500 / \mathrm{mm}^{3}$ ); all other findings were normal. Abdominal ultrasonography was negative. The patient was admitted and operated on for acute appendicitis. The appendix was inflamed, and an appendectomy was performed. On examination of the distal ileum, a Meckel's diverticulum was found and excised. No other intra-abdominal pathology was found. The patient recovered well, and was discharged on the 8th postoperative day. Histological examination showed a poorly differentiated primary adenocarcinoma of the appendix with groups of signet ring cells. The tumour had invaded the entire intestinal wall (stage Dukes B), and inflammatory changes were also present. The Meckel's diverticulum included an area of heterotopic gastric mucosa. The patient was re-admitted, and underwent right hemicolectomy as a secondary procedure. No palpable abdominal mass or signs of dissemination were found during the operation. Histological examination of the right colon and distal ileum did not prove any spread of the malignant process.
Primary malignant tumours of the appendix are found in $0.9-1.4 \%$ of all appendectomy specimens. They are classified by most authors into 5 groups: mucinous adenocarcinoma, colonic type adenocarcinoma, signet ring cell carcinoma, malignant carcinoid, and adenocarcinoid (goblet cell carcinoid). The incidence of appendiceal adenocarcinoma is $0.08 \%$ [6]. The peak incidence is in the 6th decade, similar to colorectal carcinoma, and there is a slight male predominance. Adenocarcinoma with signet ring cells - which is the most aggressive of all appendiceal adenocarcinomas and has the worst prognosis - represents $4-11 \%[1,4,5]$. It is mostly diagnosed intraoperatively, or postoperatively based on histological examination. More than $50 \%$ of patients present with acute appendicitis, but periappendiceal infiltration, palpable abdominal mass, intestinal obstruction, or some other intra-abdominal pathology can also be present. Imaging investigations (plain X-ray of the abdomen or abdominal ultrasonography) are usually of little use for diagnosing the condition.

The treatment of choice is right hemicolectomy. In specific cases, a simple appendectomy may be performed. However, according to most recent guidelines, right hemicolectomy should be performed with all non-carcinoid tumours as well as carcinoids measuring $>2 \mathrm{~cm}$ [4]. The overall 5-year survival rate, depending on tumour grade and stage, speaks for hemicolectomy (45 and $63 \%$, respectively, compared to $20 \%$ with simple appendectomy) [7,8]. Simple appendectomy can be performed only in the case of a well differentiated adenocarcinoma invading the submucosa or a poorly differentiated adenocarcinoma invading the mucosa, provided the appendiceal stump is not involved. This includes tumours of TNM stage $T_{1}$ and $T_{2}$, or stage Dukes $A$. These stages do not occur very often due to the tendency to metastasize lymphatically and hematogenously at an early stage [9]. Lymph node metastases are present in $45 \%$ of patients at the time of diagnosis [5].

\begin{tabular}{ll}
\hline KARGER & ๑ 2007 S. Karger GmbH, Freiburg \\
Fax +497614520714 & Accessible online at: \\
$\begin{array}{l}\text { E-mail Information@Karger.de } \\
\text { www.karger.com }\end{array}$ & www.karger.com/onk
\end{tabular}


Our patient had a $\mathrm{T}_{3}$ tumour (Dukes $\mathrm{B}$ ), with signet ring cells making the prognosis worse. The overall 5-year survival outcome for this histological subtype is only $18 \%$, and $55 \%$ for localized disease [4]. He underwent right hemicolectomy 4 months after appendectomy and recovered well. The relatively long interval was caused by the patient's refusal to undergo a secondary operation. Histologically, no malignant changes were found in the right colon and distal ileum, and there were no lymph node metastases.

In summary, adenocarcinoma of the appendix with signet ring cells is an extremely rare disorder that is difficult to diagnose prior to surgery. It mostly presents as acute appendicitis, and a right hemicolectomy should be performed. The prognosis depends on the tumour stage and histological grade but tends to be worse than in mucinous and colonic type adenocarcinomas. The aim of our report was to highlight the importance of searching for a Meckel's diverticulum during an appendectomy, as well as the value of histological examination of appendectomy specimen despite obvious inflammatory changes, especially in elderly patients.

\section{References}

1 Nitecky SS, Wolff BG, Schlinkert R, Sarr MG: The natural history of surgically treated primary adenocarcinoma of the appendix. Ann Surg 1994;219: $51-57$.

2 Tauro L, D'Souza CR, Fernandes H, Furtado HW, Menezes LT: Primary adenocarcinoma of the appendix. Indian J Surg 2003;65:375-377.

3 Villanueva Saenz E, Pérez-Aguirre J, Belmonte MC, Martínez PHM, Márquez RML, Carranza RJM: Appendix adenocarcinoma associated with ulcerative colitis: a case report and literature review. Tech Coloproctol 2006;10:54-56.
4 McGory ML, Maggard MA, Kang H, O'Connell JB, Ko CY: Malignancies of the appendix: beyond case series reports. Dis Col Rectum 2005;48: 2264-2271.

5 Hartley JE, Qureshi A, Monson JRT, Drew PJ, MacDonald A: Primary adenocarcinoma of the appendix. J R Soc Med 1996;89:111-113.

6 Collins DC: 71,000 human appendix specimens: a final report, summarizing forty years' study. Am J Proctol 1963;14:365-381.
7 Hesketh KT: The management of primary adenocarcinoma of the vermiform appendix. Gut 1963;4 158-168.

8 Hopkins GB, Tullis RH, Kristensen KAB: Primary adenocarcinoma of the appendix, report of seven cases and review of the literature. Dis Colon and Rectum 1973;16:140-144.

9 Hata K, Tanaka N, Nomura Y, Wada I, Nagawa H: Early appendiceal adenocarcinoma. A review of the literature with special reference to optimal surgical procedures. J Gastroenterol 2002;37:210-214. 